\title{
AMELIORATING THE TOXIC EFFECTS OF CYPERMETHRIN BY SESAME OIL IN MALE RABBITS
}

\author{
Sahar M. El-Sheshtawy ${ }^{*}$, Ghada I. A. El-Gobary², Nashwa A. Omar³, \\ Nessrin A. Shawky³
}

${ }^{1}$ Toxicology, Animal Health Research Institute, Tanta Lab, Egypt, ${ }^{2}$ Biochemistry, Animal Health Research Institute, Tanta Lab, ${ }^{3}$ Pharmacology, Animal Health Research Institute, Tanta and Zagazig Lab, Egypt.

*Corresponding author, E-mail: saharmelsheshtawy@gmail.com

\begin{abstract}
This study intended to evaluate the beneficial protective effects of sesame oil (SO) on cypermethrin (CYP)-induced sub chronic toxicity in rabbits. Male rabbits were divided into 4 groups; I: control; II: Cypermethrin (CYP, 48 mg/kg body weight, bw); III: CYP (48 mg/kg bw)+SO (1 ml/kg bw); and IV: SO (1 ml/kg bw). All treatments were orally administered three times per week for 9 weeks. CYP induced toxic effects on liver and kidney as revealed by a significant increase in serum liver enzyme activities with a significant decrease in total protein and albumin in addition to a significant increase in creatinine and uric acid levels. The effect of CYP on male fertility was demonstrated by a significant decrease in testis and epididymis weights, epididymis sperm counts, sperm motility with a significant increase in sperm abnormalities. Besides, a significant decrease in testosterone levels along with a significant increase in prolactin levels. CYP induced oxidative stress distinguished by a significant increase in malondialdehyde (MDA) levels in addition to a significant decrease in reduced glutathione (GSH) contents and superoxide dismutase (SOD) activity. Also, CYP produced a significant increase in sperm DNA damage. Co-treatment of SO with CYP improved all alterations induced by CYP. In conclusion SO has beneficial protective effects as it tends to dampen CYP sub chronic toxicity in male rabbit.
\end{abstract}

Key words: sesame oil; cypermethrin; oxidative stress; male fertility; rabbit

\section{Introduction}

Cypermethrin (CYP) is synthetic pyrethroid widely used in agriculture. Due to the lipophilic nature of pyrethroid insecticides, they conglomerate in biological membranes (1), resulting in stimulation of free radical formation leading to oxidative stress in mammals (2). CYP is absorbed via the gastrointestinal and respiratory tracts and confers discriminatory distribution into lipid-rich internal tissues (3). CYP initially thought to be unharmed for household implementation, however later a number of reports displayed its reproductive poisoning in mammalian and non-mammalian laboratory and wildlife animal species (4). The reproductive toxicity of CYP is a major concern because spermatogenesis may be vulnerable to chronic exposure to chemicals at very low dose. Due to existence of CYP as lipid soluble and of 
small size, it passes through cell membrane and may damage DNA $(5,6)$. It was found that CYP raises the chromosomal deviation, and micronuclei in human peripheral lymphocytes (7) and has adverse effects on male adult rats reproduction by decreasing testicular weight, epididymis sperm counts, and motility $(8,9)$.

Sesame (Sesame indicum) has phenolic compounds, non-protein amino acids, alkaloids, cacogenics glycosides, polyunsaturated fats and lipids, mucilage, phospholipids, thiazole, disulphide, ketones, aldehyde, vitamins as B1, B2, C and $\mathrm{E}$ and trace elements such as calcium, magnesium,iron, copper, zinc and phosphorus (10, 11). Sesame contains abundant lignans like lipid-soluble lignans (sesamin and sesamolin), sterol and water-soluble lignan glycosides (sesaminol triglucoside and sesaminol diglycoside) with varied antioxidant attributes which have the capability to improve fertility potency of male reproductive system. (12). Sesame seed could improve the adverse effects of reactive oxygen species on testicular parameters (13, 14). Sesame has protective role on the male reproductive tract due to binding to the estrogen receptors (ER) and modification of androgen receptor (AR) activity in the testis $(15,16)$.

Therefore, this study was performed to evaluate the toxic effects of CYP on liver and kidney function, male reproductive toxicity in male rabbits and its amelioration by sesame oil.

\section{Materials and methods}

\section{Materials}

Cypermethrin (10\% E.C, C22H19C12NO3, molar mass $416.30 \mathrm{~g} / \mathrm{mol}$, synthetic pyrethroid. $\alpha$-cyano-3-phenoxybenzyl (1RS) - cis, trans- 3(2,2-diclorovinyl)-2, 2-dimethyl-cyclopropane carboxylate, $10 \%$ purity) was purchased from Cenavisa Laboratorios Cemi Pendra Estela s/n 43205 Reus (Spain). Sesame oil was obtained from Cap. pharm.

\section{Experimental animals}

Twenty eight sexually-mature, healthy White New Zealand rabbits 6-8 months old, weighting about $2.000-2.100 \mathrm{~kg}$ with clinically normal genitalia and apparently healthy were obtained from private farm and were kept in stainless steel wire mesh cages under sanitary hygienic conditions. The room temperature was kept at $25-27^{\circ} \mathrm{C}$ with $45-70 \%$ humidity and 12 $\mathrm{h}$ light .The rabbits were fed on a standard pelleted ration according to $(17,18)$ with chemical composition of Crude protein \% 18, Digestible energy Kcal $/ \mathrm{kg}$ of diet 2600, Crude fiber \% 1012, Calcium \% 1.2, Phosphorus \% 0.8 Lysine \% 0.75 , Methionine and \% 0.65cysteine. The drinking water was available ad libitum throughout the study and being acclimatized for two weeks prior to the experiment.

\section{Experimental design}

Rabbits were allocated into 4 equal groups (7/group). All treatments were applied orally three times per week for 9 weeks to cover all the spermatogenesis period.The rabbits in the first group were considered as control and not given any treatment. The second group received CYP [48 mg/kg bw (19)].The third group was given CYP $(48 \mathrm{mg} / \mathrm{kg} \mathrm{bw})+\mathrm{SO}[1 \mathrm{ml} / \mathrm{kg}$ bw (20)]. The fourth group was administered SO (1 $\mathrm{ml} / \mathrm{kg}$ bw). Body weight was recorded in the non-fed state at the beginning of study (initial weight) and at time before slaughter (final weight). Weight earning (final body weight (g)- primary body weight (g) was calculated.

\section{Blood samples}

Blood samples were collected at end of experimental period (9 weeks). Blood samples were gathered from the marginal ear vein using vacuum tubes, left to coagulate and then centrifuged at $3000 \mathrm{rpm}$ for $10 \mathrm{~min}$. The sera were then stored frozen at $-20^{\circ} \mathrm{C}$ until the biochemical analysis.

\section{Biochemical assays}

Serum levels of liver damage enzymes [aspartate aminotransferase (AST), alanine amino transferase (ALT), and alkaline phosphates (ALP)], kidney function parameters (Urea, uric acid and creatinine), albumin, total protein, calcium, sodium, potassium and magnesium, superoxide dismutase (SOD), reduced glutathione (GSH), and Malondialdehyde (MDA) were determined using commercially available kits and as previously described $(19,20)$. Serum total testosterone and prolactin levels were assessed 
by Enzyme Linked Immunosorbent Assay (ELISA) as depicted by (21).

\section{Seminal examination}

After blood sampling, rabbits were slaughtered and seminal fluid were collected from the epididymis for seminal examination as previously described $(21,22)$.

\section{Comet assay}

Testes were examined for DNA damage using comet assay (single-cell gel electrophoresis) as previously described (23).

\section{Statistical analysis}

One-way analysis of variance using GraphPad Prism 7 (GraphPad Software, Inc, La Jolla, CA) was used to determine the difference between the groups. Comparison of means was carried out with Tukey's honestly significant difference test. Data were presented as mean \pm standard error of mean (SEM) and significance was declared at $P<0.05$.

\section{Results and discussion}

\section{Body weight}

Table (1) showed a notable decrease in the body weight of CYP- treated groups. Co-treatment of SO and CYP resulted in a significant increase in the body weight when compared to CYP-treated group. These results were in agreement with $(24,25)$ in rats and in rabbits (26).

The decrease in body weight of CYP treated group may be resulted from the effect of insecticide pyrethroid on gastrointestinal tract which subsequently leads to decrease in appetite and absorption of nutrients from gut (27). This decrease related to the liver injury (28). Also CYP intake may has a combined action of cholinergic (decrease feed intake and diarrhea) and oxidative stress and/or due to increase in breakdown of lipids and proteins as a direct effect of CYP pesticide exposure (29). (30) noted changes in epithelial cells and mucosal layer of digestive tract, resulting in reduced appetite and growth rate. Sesame oil rich in several antioxidants and chemo-preventive agents such as tocopherol, sesamolin, sesaminol and sesamin as well as mono-unsaturated and polyunsaturated fatty acids, rich in vitamin A, B and E as well as iron, calcium, magnesium and copper (31). All these compounds may be the cause which lead to a relatively positive effects and decrease the negative effect of CYP.

\section{Biochemical investigation}

The serum levels of ALT, AST and ALP in CYP intoxicated group were significantly increased in comparison with the control group (Table 2). In consistence, previous studies also showed similar increased in liver enzyme activities in CYP intoxication (32). Exposure to pesticide causes disruption of hepatic cell and leakage of enzymes from hepatocytes to blood (33). Increases of serum liver enzymes usually indicate liver damage (34). We also found that administration of SO with CYP significantly decreased these enzyme. SO is hepato-protective, anti-inflammatory, and can decrease lipid peroxidation by decreasing free radicals and increasing antioxidant properties (35).

Administration of CYP significantly increased urea, creatinine and uric acid (Table 2). Co-supplementation of SO with CYP showed a significant decrease in urea, creatinine and uric acid in comparison with CYP -intoxicated group. These results were in agreement with those reported by other studies (36). An elevation of blood creatinine level is associated with kidney damage which agree with results reports by (37). Sesame oil has an ameliorative effect as it decrease the negative effect of CYP. This may be due to its anti-inflammatory antioxidant properties (35). CYP intoxication significantly decreased total protein and albumin (Table 2). Co-administration of SO with CYP restored CYP effects towards normal levels. These results agree with $(38,39)$.

CYP intoxication significantly decreased calcium and sodium and increased potassium and magnesium levels in serum (Table 2). Cosupplementation of SO with CYP showed a significant elevation in calcium and sodium levels with significant decline in potassium and magnesium levels when compared to CYP-treated group. This result was parallel to that of (40). Increased potassium level could be due to CYP 
effect on potassium channel leading to an alteration in the activation potential (41). The benefits effects of SO could be due to its profusion of antioxidant which interfere with renin-angiotensin system (42). Sesame oil induced significant increase in serum magnesium level 1 and this disagreed with the results of (43).

CYP intoxication significantly decreased testosterone and significantly elevated prolactin (Table 2). SO decreased this negative effect of CYP. Similar effect was reported by (44) who found that exposure to CYP significantly decreased testosterone synthesis. Decrease in testosterone revealed extra testicular target by pesticides and also suggests central effect for pesticides on hypothalamus pituitary axis (45). The Luteinizing hormone (LH) induced leydig cells to produce testosterone and so, decrease in $\mathrm{LH}$ inhibit testosterone production. Moreover, low testosterone, follicular stimulating hormone (FSH) and LH levels inhibit effective spermatogenesis and evolution of seminiferous tubules, thus causing infertility (46).

CYP inducted a significant elevation in serum levels of MDA in addition to a significant decline in reduced glutathione (GSH) contents and superoxide dismutase (SOD) activity as compared to the control group (Table 3). Cotreatment of SO with CYP mitigated the adverse effects of CYP toward control levels. (47) found that CYP inducted significant elevations in serum MDA, SOD and significant decline in serum GSH levels. This oxidative damage was normalized by co-administration of SO with CYP, where SO provided observed protection against oxidative stress induced by CYP and this agreed with (48).

\section{Sperm count and abnormalities}

There were marked sperm deformities in head and tail of CYP treated group as compared to the control group (Table 4). This result agreed with $(9,49)$. This may be due to inhibition of LH and FSH levels $(9,50)$. Degenerated stereo cilia and focal mononuclear cellular infiltration without any spermatozoa in epididymis were noticed following CYP treatment in rabbits (51). Co-treatment of SO mitigated the adverse effects of CYP toward control levels. This result agreed with (52) and may be attributed to the antioxidant properties of SO.

\section{Weight of testes and epididymis}

CYP induced a significant decrease in testicular and epididymis index weight when compared to the control (Table 4). The same results was recorded by (8). SO induced significant increase in testicular weight which may be due to increase in testosterone level, which can be lead to increased discrimination for leydig cells which stimulated by the increase in LH and thus increase testicular weight. Also, there was significant increase in epididymis weight which may be due to increase in number of protein receptors specific to testosterone which leads to increase epididymis weight (53).

Table 1: Initial and final body weight of male rabbits exposed to Cypermethrin three times/week for 9 weeks and the protective effect of Sesame oil $(n=7)$

\begin{tabular}{|l|c|c|c|c|c|}
\hline & Control & CYP & CYP + SO & SO & P value \\
\hline $\begin{array}{l}\text { Initial body } \\
\text { weight (gm.) }\end{array}$ & $2070 \pm 97.46$ & $2065 \pm 84.45$ & $2060 \pm 54.77$ & $2080 \pm 103.68$ & 0.958 \\
\hline $\begin{array}{l}\text { Final body } \\
\text { weight(gm.) }\end{array}$ & $3008 \pm 51.18$ & $2100 \pm 139.82$ & $2600 \pm 45.82$ & $2900 \pm 15.811$ & $0.00001^{*}$ \\
\hline $\begin{array}{l}\text { Weight gain } \\
\text { (gm.) }\end{array}$ & $930 \pm 3.082$ & $40 \pm 122.678$ & $550 \pm 62.048$ & $820 \pm 7.905$ & $0.00001^{*}$ \\
\hline
\end{tabular}

The result is significant at $\mathrm{p} \leq 0.05$. CYP: Cypermethrin, SO: Sesame oil 
Table 2: Serum biochemical parameters of male rabbits exposed to CYP and the protective effect of SO

\begin{tabular}{|l|l|l|l|l|}
\hline & Control & SO & CYP + SO & CYP \\
\hline AST (U/L) & $52.5 \pm 2.32$ & $33.75 \pm 10.05$ & $61.5 \pm 0.96^{*}$ & $104.0 \pm 3.58^{* *}$ \\
\hline ALT(U/L) & $31.5 \pm 0.65$ & $27.5 \pm 1.85$ & $44.23 \pm 1.47^{*}$ & $81.25 \pm 1.93^{* *}$ \\
\hline ALP(U/L) & $111 \pm 5.91$ & $112.8 \pm 2.62$ & $117.5 \pm 4.94^{*}$ & $395.7 \pm 13.01^{* *}$ \\
\hline TP (g/dl) & $4.57 \pm 0.11$ & $4.65 \pm 0.15$ & $4.15 \pm 0.06^{*}$ & $3.48 \pm 0.193^{*}$ \\
\hline Alb. (g/dl) & $2.85 \pm 0.64$ & $3.32 \pm 0.11$ & $2.95 \pm .0 .064^{*}$ & $1.97 \pm 0.06^{*}$ \\
\hline $\mathrm{Cr} .(\mathrm{mg} / \mathrm{dl})$ & $0.68 \pm 0.05$ & $0.69 \pm 0.05$ & $1.29 \pm 0.21^{*}$ & $2.39 \pm 0.186^{* *}$ \\
\hline $\mathrm{Urea}(\mathrm{mg} / \mathrm{dl})$ & $17.0 \pm 0.82$ & $15.5 \pm 1.32$ & $36.75 \pm 1.65 * *$ & $91.5 \pm 9.31^{* *}$ \\
\hline $\mathrm{UA} \mathrm{(mg/dl)}$ & $3.48 \pm 0.25$ & $3.6 \pm 0.11$ & $3.7 \pm 0.12^{*}$ & $4.32 \pm 0.14^{* *}$ \\
\hline $\mathrm{Ca}(\mathrm{mg} / \mathrm{dl})$ & $8.35 \pm 0.23$ & $9.95 \pm 0.22^{*}$ & $8.92 \pm 0.11^{*}$ & $7.8 \pm 0.20^{*}$ \\
\hline $\mathrm{Na}(\mathrm{mmol} / \mathrm{L})$ & $131.0 \pm 0.91$ & $134.0 \pm 1.87$ & $128.25 \pm 0.63^{*}$ & $114.7 \pm 2.56^{*}$ \\
\hline $\mathrm{K}(\mathrm{mmol} / \mathrm{L})$ & $4.0 \pm 0.09$ & $4.3 \pm 0.39$ & $5.1 \pm 0.07^{*}$ & $6.95 \pm 0.2^{* *}$ \\
\hline $\mathrm{Mg}(\mathrm{mg} / \mathrm{dl})$ & $2.0 \pm 0.09$ & $2.35 \pm 0.06$ & $2.23 \pm 0.08$ & $2.82 \pm 0.48$ \\
\hline $\mathrm{Testo}(\mathrm{ng} / \mathrm{ml})$ & $3.53 \pm 0.28$ & $7.67 \pm 0.48^{*}$ & $4.25 \pm 0.14$ & $2.48 \pm 0.31^{*}$ \\
\hline $\mathrm{Prol}(\mathrm{ng} / \mathrm{ml})$ & $10.5 \pm 0.96$ & $8.75 \pm 0.75$ & $13.0 \pm 1.22$ & $19.75 \pm 1.65^{* *}$ \\
\hline
\end{tabular}

*Significant at $(\mathrm{P} \leq 0.05) * *$ Significant at $(\mathrm{P} \leq 0.01)$. Results are represented as mean \pm standard error. CYP: Cypermethrin, SO: Sesame oil, AST: Aspartate transaminase, ALT: Alanine transaminase, ALP: Alkaline phosphatase, TP: total protein, Alb.: albumin, Cr: creatinine, UA: Uric acid, Ca: Calcium, Na: Sodium, Mg: magnesium, Testo: Testosterone, Prol: Prolactin.

Table 3: Lipid peroxide (MDA), super oxide dismutase (SOD) and reduced glutathione (GSH) of male rabbits exposed to CYP and the protective effect of $\mathrm{SO}$

\begin{tabular}{|l|l|l|l|l|}
\hline & MDA $(\mathrm{nmol} / \mathrm{ml})$ & $\mathrm{SOD}(\mu / \mathrm{ml})$ & $\mathrm{GSH}(\mu / \mathrm{ml})$ & P value \\
\hline Control & $4.48 \pm 0.486$ & $29.5 \pm 1.516$ & $1.096 \pm 0.145$ & $0.00001^{*}$ \\
\hline CYP & $7.88 \pm 0.178$ & $20.4 \pm 1.14$ & $1.008 \pm 0.078$ & $0.00001^{*}$ \\
\hline CYP+SO & $5.22 \pm 0.349$ & $25.6 \pm 1.140$ & $0.794 \pm 0.072$ & $0.00001^{*}$ \\
\hline SO & $3.10 \pm 0.200$ & $34.0 \pm 1.581$ & $1.300 \pm 0.700$ & $0.00001^{*}$ \\
\hline
\end{tabular}

*Significant at $(\mathrm{P} \leq 0.05)$. Results are represented as mean \pm standard error MDA: Malondialdehyde, SOD: Superoxide dismutase, GSH: Reduced glutathione, CYP: Cypermethrin, SO: Sesame oil 
Table 4: Weight of sexual organs and epididymis sperm characters in male rabbits exposed to CYP and the protective effect of SO

\begin{tabular}{|l|l|l|l|l|}
\hline & Control & Cypermethrin & $\begin{array}{l}\text { Cypermethrin } \\
+ \text { Sesame oil }\end{array}$ & Sesame oil \\
\hline Weight of testes(gm.) & $5.09 \pm 0.116^{*}$ & $4.138 \pm 0.03^{*}$ & $4.304 \pm 0.071^{*}$ & $4.952 \pm 0.09^{*}$ \\
\hline Weight of epididymis & $1.80 \pm 0.100^{*}$ & $0.87 \pm 0.66^{*}$ & $1.118 \pm 0.13^{*}$ & $1.66 \pm 0.114^{*}$ \\
\hline $\begin{array}{l}\text { Sperm concentration } \\
\left(10^{6} \mathrm{~mm}^{3}\right)\end{array}$ & $34.86 \pm 2.84$ & $12.73 \pm 1.74 * *$ & $22.3 \pm 5.04^{*}$ & $33.6 \pm 3.48$ \\
\hline Sperm mortality\% & $87.6 \pm 3.89$ & $57.7 \pm .4 .14^{* *}$ & $72.0 \pm 3.25^{*}$ & $85.0 \pm 4.12$ \\
\hline Life sperm\% & $86.0 \pm 3.22$ & $50.7+5.6^{* *}$ & $64.0 \pm 2.53^{*}$ & $80.0 \pm 3.88$ \\
\hline Sperm abnormality $\%$ & $11.01 \pm 0.28^{*}$ & $20.41 \pm 0.52^{* *}$ & $15.01 \pm 0.18^{*}$ & $9.21 \pm 0.23^{*}$ \\
\hline
\end{tabular}

*Significat difference at $(\mathrm{P} \leq 0.05) * *$ Significant at $(\mathrm{P} \leq 0.01)$
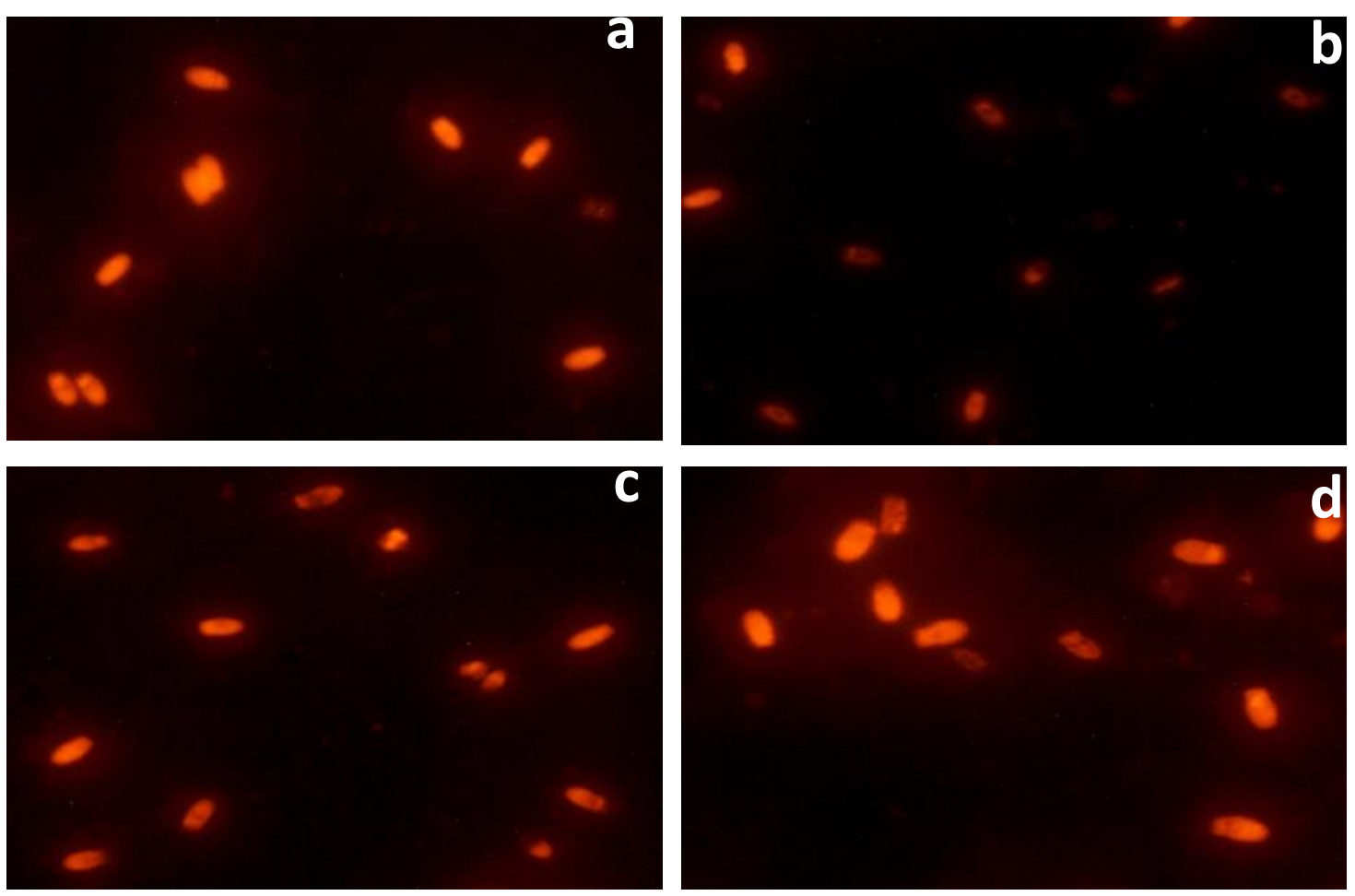

Figure 1: Comet assay results. a. Group (I) showing high incidence of genetically intact sperms. b. Group (II) displaying high incidence of genetically damaged sperms. c. Group (III) exhibiting a reduction in number of genetically degenerated sperms. d. Group (IV) revealing appearance of few genetically degenerated sperms. X 400

\section{Comet assay}

Figure 1 shows the negative effects of CYP and the defensive effects of SO on sperm DNA.
The likely mechanism of pyrethroids to produce sperm DNA deterioration; may be due to their decreased molecular size and hydrophobic nature, so they cross blood testicular barrier and 
reach the sperm nucleus (5). Pyrethroids have been shown to induct oxidative stress by generating free radicals which are the main cause of DNA damage (54).

\section{Conclusion}

This study confirms that SO has a beneficial protective effects as it tends to dampen CYP sub chronic toxicity in male rabbits through improvement of body weight, serum biochemical, antioxidant parameters, sperm characters as well as sperm DNA damage.

\section{Acknowledgment}

Many thanks for Prof. Dr. Mohammed Arafa, Biochem. Dep. Animal Health Research Institute Dokki for helping in the preparation and estimation of blood biochemistry.

\section{References}

1. Michelangeli FM, Robson MJ, East JM. Lee AG. The conformation of pyrethroids bound to lipid bilayers. Biochimica et Biophysica Acta. 1990;1028 (1):49-57.

2. Mossa AT H, Refaie AA, Ramadan A. and, Bouajila J. Amelioration of prallethrin-induced oxidative stress and hepatotoxicity in rat by the administration of Origanum majorana essential oil. BioMed Research International 2013; 2013:11.

3. Soderlund DM, Clark JM, Sheets LP, Mullin LS, Piccirillo VJ, Sargent D. Mechanisms of pyrethroid neurotoxicity: implications for cumulative risk assessment. Toxicology 2002; 171(1):53-9.

4. WHO. Pesticides and Health in the Americas. Washington, DC, USA: World Health Organization; 1993. (Environment Series no. 12).

5. Saxena PN, Chauhan LKS, Gupta SK. Cytogenetic effects of commercial formulation of cypermethrin in root meristem cells of Allium sativum: Spectroscopic basis of chromosome damage. Toxicology 2005; 216: 244-52.

6. Sharaf S, Khan A, Khan MZ, Aslam F, Saleemi MK, Mahmood F. Clinico-hematological and micronuclear changes induced by cypermethrin in broiler chicks: Their attenuation with vitamin $\mathrm{E}$ and selenium. Exp. Toxicol. Pathol 2010; 62: 33341.

7. Kocaman AY, Topaktao M. The in vijtro genotoxic effects of a commercial formulation of alphacypermethrin in human peripheral blood lymphocytes. Environ Mol Mutagen 2009; 50:27-36.
8. Mani U, Islam F, Prasad AK, Suresh Kumar V, Maji BK, Dutta KK. Steroidogenic alterations in testes and sera of rats exposed toformulated fenvalerate by inhalation. Hum Exp Toxicol 2002; 21:593-7.

9. Yasser SM, Inam BF, Nazih WZ. Toxicological effects of cypermethrin on sperm morphology in male rabbit.International Journal of Advanced Research in Biological Sciences 2016; 3 (10): 46-51.

10. Shittu L, Shittu RK, Olufemi O, Tayo AO, Osunubi AAA. Hypoglycaemia and improved testicular parameters in Sesamum radiatum treated normo-glycaemic adult male Sprague Dawley rats. African Journal of Biotechnology 2009; 8(12):2878-86.

11. Konan A, Datte J, Yapo P. Nitric oxide pathway-mediated relaxant effect of aqueous sesame leaves extract (Sesamum radiatum Schum. \& Thonn.) in the guinea-pig isolated aorta smooth muscle. BMC complementary and alternative medicine 2008; 8 (1):23.

12. Shittu L, Bankole MA, Oguntola JA, Ajala O, Shittu RK. Sesame leaves intake improve and increase epididymal spermatocytes reserve in adult male Sprague Dawley rat. Scientific Research and Essays 2007; 2(8):319-24.

13. Rubio J, Riqueros MI, Gasco M, Yucra S, Miranda S. Lepidium meyenii (Maca) reversed the lead acetate induced damage on reproductive function in male rats. Food and Chemical Toxicology 2006; 44(7):1114-22.

14. Jeng K, Hou R. Sesamin and Sesamolin: Natures therapeutic lignans. Current Enzyme Inhibition. 2005 ; 1(1): 11-20.

15. Shittu L, Shittu R, Adesite S, Ajala MO, Bankole M. Fitoestregen os Sesame radiatum Estimulan la Actividad Espermatogenica y Mejoran la Calidad del Esperma en el Testiculo de Ratas Sprague Dawley Adulto de Sexo Masculino. International Journal of Morphology 2008; 26(3):643-52.

16. Soliman MM, Attia HF, Ghada A Abou ElElla. Genetic and histopathological alterations induced by cypermethrin in rat kidneyand liver: Protection by sesame oil.International Journal of Immunopathology and Pharmacology 2015; 28(4) 508-20.

17. AOAC (Association of Official Analytical Chemists) (1990) Official Methods of Analysis. Washington DC.

18. National Research Council NRC (1995) Nutrient Requirement of Laboratory Animals. 4th Revised Edition, National Academy Press, Washington DC. 
19. Abdelhady D H, El-Magd M A, Elbialy Z I, Saleh A A. Bromuconazole-induced hepatotoxicity is accompanied by upregulation of PXR/CYP3A1 and downregulation of CAR/CYP2B1 gene expression, Toxicol Mech Methods 2017; 27(7): 544-50.

20. Alzahrani F A, El-Magd M A, AbdelfattahHassan A, Saleh A A, Saadeldin I M, El-Shetry E S, Badawy A A, Alkarim S. Potential Effect of Exosomes Derived from Cancer Stem Cells and MSCs on Progression of DEN-Induced HCC in Rats, Stem Cells International 2018; 2018: 17 https://doi.org/10.1155/2018/8058979.

21. El-Magd M A, Kahilo K A, Nasr N E, Kamal T, Shukry M, Saleh A A. A potential mechanism associated with lead-induced testicular toxicity in rats, Andrologia 2016; 49(9): e12750.

22. Almadaly E A, Farrag F A, Saadeldin I M, El-Magd M A, El-Razek I M A. Relationship between total protein concentration of seminal plasma and sperm characteristics of highly fertile, fertile and subfertile Barki ram semen collected by electroejaculation, Small Ruminant Research 2016; 144: 90-9.

23. Badawy A A, El-Magd M A, AlSadrah S A. Therapeutic Effect of Camel Milk and Its Exosomes on MCF7 Cells In Vitro and In Vivo, Integrative Cancer Therapies 2018; 7(4): 1235-46.

24. Hussain S, Khan MZ, Khan A, Javed I, Asi MR. Toxico-pathological effects in rats induced by concurrent exposure to aflatoxin and cypermethrin. Toxicon. 2009; 53:33-41.

25. Sangha GK, Kaur K, Khera KS, Singh B. Toxicological effects of cypermethrinon female albino rats. Toxicol Int 2011; 18: 5-8.

26. Lakkawar AW, Chattopadhyay SK, Somuanshi R. Experimental cypermethrintoxicity in rabbits- a clinical and patho-anatomical study. Folia Veterinaria 2004;48:3-8.

27. Sangha GK, Kaur K, Khera KS. Cypermethrin induced pathological and biochemical changes in reproductive organs of female rats. Journal of Environmental Biology 2013; 34 (1): 99-105.

28. Sankar P, Telang AG, Manimaran A. Protective effect of curcumin on cypermethrin-induced oxidative stress in Wistar rats. Experimental Toxicology Pathology. 2012; 64:487-93.

29. Adjrah Y, Simplice D, Karou, Agbonon A, Ameyapoh Y, Souza C., Gbeassor M. Effect of cypermethrin-treated lettuce (Lactuca sativa) on wistar rat Liver. Journal of Applied Pharmaceutical Science 2013; 3 (1): 128-32.

30. Khillare YK, Wagh SB. Acute toxicity of pesticides in the freshwater fish Barbus stigma: histopathology of the stomach. Uttar Pradesh J. Zool.
1988; 8 (2), $176-9$.

31. Choi AM, Lee SB, Cho SH, Hwang I, Hur $\mathrm{CG}$, Suh MC. Isolation and characterization of multiple abundant lipid transfer protein isoforms in developing sesame (Sesamum indicum ) seeds. Plant Physiol Biochem 2008 ;46(2): 127-139.

32. Kanbur M, Eraslan G, Ince S, Altintaş L, Liman B, Bayram L. The Effects of Propetamphos, Cypermethrin and Propetamphos-Cypermethrin Combination on Some Biochemical and Histopathological Parameters in Mice. Kafkas Universitesi Veteriner Fakultesi Dergisi 2015;21(2):187-94.

33. Heikal TM, Mossa TH, Rasoul MAA, Marei GIKH THE Ameliorating Effects of Green Tea Extract Against Cyromazine and Chlorpyrifos Induced Liver Toxicity in Male Rats. Asian Journal of Pharmaceutical and Clinical Research 2013;6 (1): $48-55$.

34. Yousef MI, Awad TI, Mohamed EH. Deltamethrin-induced oxidative damage and biochemical alterations in rat and its attenuation by Vitamin E. Toxicology 2006; 227: 240-24.

35. Huang YS. Open, sesame! The gateway to mitigate hepatic injury using sesamin. J Chinese Med Asso 2014;77: 219-20.

36. Sakr SA, Albarakai AY. Effect of cinnamon on cypermethrin-induced nephrotoxicity in albino rats. International Journal of Advanced Research 2014; 2 (7): 578-6.

37. Ambali SF, Abubakar AT, Shittu M, Yaqub LS, Anafi SB, Abdullahi A. Chlorpyrifos-induced alteration of hematological parameters in Wistar rats: Ameliorative effect of Zinc. Journal of Environmental Toxicology 2010; 4: 55-66.

38. Veerappan M, Hwang I, Pandurangan M. Effect of cypermethrin, carbendazim and their combination on male albino rat serum. International Journal of Clinical and Experimental Pathology 2012; 93: 361-9

39. Mhya DH, Umar IA, Onyike E. Anti-peroxidative and Biochemical Protective Activity of Khaya Senegalensis Stem Bark Extract on Rats Fed Pesticideinfused feed. International Journal of Pharma Sciences and Research 2014; 5 (7): 385-90.

40. Mishra D, Tripathi S, Srivastav SK, Suzuki N, Srivastav AK. Corpuscles of Stannius of a teleost Heteropneustes fossilis following intoxication with a pyrethroid (cypermethrin). North-Western Journal of Zoology 2010; 6 (2): 203-8.

41. Singh AK, Tiwaril MN, Prakash O, Singh MP. A Current Review of Cypermethrin-Induced Neurotoxicity and NigrostriatalDopaminergic Neurodegeneration. Current Neuropharmacology 2012; $10,64-71$. 
42. Sankar D, Ramakrishna Rao M, Sambandam G, Pugalendi KV. Effect of Sesame Oil on Diuretics or B-blockers in the Modulation of Blood Pressure, Anthropometry, Lipid Profile, and Redox Status. Yale Journal of Biology and Medicine 2006; 79, 19-26.

43. Yanagisawa F, Ogasawara K. Biochemical Studies on Plant Oil, Electrolyte Metabolism. EiyoToShokuryo, 1967; 20(4), 307-310.Online ISSN : 1883-63.

44. Hua Wang, Qun Wang, Xian-Feng Zhao, Ping Liu, Xiu-Hong Meng, Tao Yu, Yan-Li Ji, Heng Zhang, Cheng Zhang, Ying Zhang, De-Xiang Xu. Cypermethrin exposure during puberty disrupts testosterone synthesis via down regulating StAR in mouse testes .Arch Toxicol 2010; 84:53-61.

45. Sharma P, Huq AU, Singh R. Cypermethrininduced reproductive toxicity in the rat is prevented by resveratrol. J. Hum. Reprod. Sci 2014; 7: 99-106.

46. Monet-Kuntz C, Hochereau-de Reviers MT, Terqui M. Variations in testicular androgen receptors and histology of the lamb testis from birth to puberty. J. Reprod. Fertil 1984; 70: 203-10.

47. Eraslan G, Kanbur M, SiliğY, Karabacak M, SoyerSarica Z, Şahin S. The acute and chronic toxic effect of cypermethrin, propetamphos, and their combinations in rats. Environ Toxicol.2016; 31(11):1415-1429. doi: 10.1002/tox.22147. Epub 2015 Apr 30.
48. Abdou HM, Hussien HM, Yousef MI. Deleterious effects of cypermethrin on rat liver and kidney: protective role of sesame oil. J Environ Sci Health B 2012;47(4): 306-14.

49. Mahdi YS, Falih IB, Zaid NY. Toxicological effects of cypermethrin on sperm morphology in male rabbit. International Journal of Advanced Research in Biological Sciences 2016; 3 (10), 46-51.

50. Joshi SC, Bansal B, Jasuja ND. Evaluation of reproductive and developmental toxicity of cypermethrin in male male albino rats. Toxicol Environ Chem. 2011; 93:593-602.

51. Neelam Bansal, Varinder Uppal, Opinder Singh, Roy KS. Toxic effect of cypermethrin on the urogenital organs of male rabbits.Royal Veterinary Journal of India 2005; 1 (1): 28-30.

52. Mahabadi JA, Bafrani HH, Nikzad H. Effect of sesame supplemented diet on prostate and seminal vesicle histology of adult rat. Int. J. Morphol 2016; 34(2):604-9.

53. AL-Sallami ASM. Effect of Sesame Oil on Male Rats Treated with Acrylamide in some Physiological and Hormonal Blood Criteria, International Journal of Current PharmaceuticalReview and Research IJCPR, 2017;8(2), 134-40.

54. Giray B, Gürbay A, Hincal F. Cypermethrin-induced oxidative stress in rat brain and liver is prevented by vitamin $\mathrm{E}$ or allopurinol. Toxicol Lett 2001; 118:139-46. 